\title{
Fabrication and Performance Test of Aluminium Alloy-Rice Husk Ash Hybrid Metal Matrix Composite as Industrial and Construction Material
}

\author{
Md. Rahat Hossain, Md. Hasan Ali, Md. Al Amin, Md. Golam Kibria, and Md. Shafiul Ferdous
}

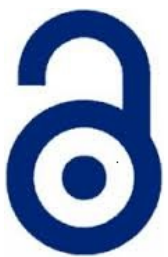

ABSTRACT

Aluminium matrix composites ( $A M C S)$ used extensively in various engineering fields due to their exceptional mechanical properties. In this present study, aluminium matrix composites ( $A M C S)$ such as aluminium alloy $(A 356)$ reinforced with rice husk ash particles $(R H A)$ are made to explore the possibilities of reinforcing aluminium alloy. The stir casting method was applied to produce aluminium alloy $(A 356)$ reinforced with various amounts of $(2 \%$, $4 \%$, and $6 \%$ ) rice husk ash (RHA) particles. Physical treatment was carried out before the rice husk ash manufacturing process. The effect of mechanical strength of the fabricated hybrid composite was investigated. Therefore, impact test, tensile stress, compressive stress, and some other tests were carried out to analyse the mechanical properties. From the experimental results, it was found that maximum tensile, and compressive stress were found at $6 \%$ rice husk ash $(R H A)$ and aluminium matrix composites $(A M C s)$. In future, the optimum percentages of rice husk ash $(R H A)$ to fabricate the hybrid composites will be determined. Also, simulation by finite element method (FEM) will be applied for further investigation.

Keywords. Rice Husk Ash (RHA), Aluminium Matrix Composites (AMCs), Stress.

\section{INTRODUCTION}

Composites has become the most widely used materials because of their adaptability in different conditions. Also, the relative ease of combination with other materials to show exhibit exceptional properties to serve different purpose. The development of low cost aluminium matrix composites reinforced with environmentally friendly material has been one of the major innovations in the field of materials to curtail environmental pollution. Aluminium matrix composites $(A M C S)$ were developed to improve the performance of conventional aluminium alloys which cannot meet the requirement of modern engineering products. Aluminium matrix composites (AMCs) exhibit high strength, high elastic modulus and good wear resistance compared to the without reinforced aluminium alloys. Aluminium matrix composites ( $A M C S$ ) are increasingly used to produce several components in aerospace, automotive, marine and nuclear industries [1-3]. Aluminium matrix composites (AMCS) have emerged as a class of

\section{R. Hossain}

Graduate School of Industrial Engineering \& Management

Khulna University of Engineering \& Technology, Khulna 9203, Bangladesh

E-mail: rudrorahat50@gmail.com

\section{H. Ali $\square$}

Department of Industrial and Production Engineering

Bangladesh Army University of Science and Technology, Saidpur 5310, Bangladesh

E-mail: hasankuet38@gmail.com

M. A. Amin' and M. G. Kibria ${ }^{2}$

Department of Industrial Engineering \& Management

Khulna University of Engineering \& Technology, Khulna 9203, Bangladesh

'E-mail: alaminkuet01@gmail.com

2E-mail: kibria05_ruet@yahoo.com

\section{S. Ferdous}

Department of Mechanical Engineering

Bangladesh Army University of Science and Technology, Saidpur 5310, Bangladesh

E-mail: munazeer_218@yahoo.com

Reference: Hossain, M. R., Ali, M. H., Amin, M. A., Kibria, M. G., and Ferdous, M. S. (2017). Fabrication and Performance Test of Aluminium Alloy- Rice Husk Ash Hybrid Metal Matrix Composite as Industrial and Construction Material. International Journal of Engineering Materials and Manufacture, 2(4), 94-102. 
materials capable of advanced structural, aerospace, automotive, electronics, thermal management, and wear applications.

Rice husk ash is one of the most inexpensive, and low-density reinforcement that contain $\mathrm{SiC}, \mathrm{Al}_{2} \mathrm{O}_{3}$ etc. Also, available in large quantities as solid waste by-product. Therefore, its efficient utilization is urgently needed to avoid environmental pollution. Rice husk is an agricultural residue from the rice milling process. A huge amount of rice husk ash (RHA) are produced every year across the world. Therefore, the effective utilization of this agricultural waste will protect the environment. Nowadays, aluminium is being widely used in construction, household purpose like windows and doorframe, automobiles, electronic equipment, and other devices. The cost of effective production, improving the strength, and its feasibility analysis is the ultimate goal of this research. In this study, our main approach is to fabricate a hybrid composite that enhances the various physical properties rather than normal metal alloy.

Itskos et al. investigated that $A 356$ alloy or its similar alloy is used as a matrix for obtaining composites, which have an enhanced wear resistance, promising mechanical properties at room temperature. Also, have enhanced mechanical properties at elevated temperatures [4].

Prasad et al. shows the damping performance of hybrid composites using dynamic mechanical analyzer (DMA) [5]. The composites were fabricated with $2 \%, 4 \%, 6 \%$, and $8 \%$ by weight of rice husk ash $(R H A)$, and $\mathrm{SiC}$ in equal proportions using two stages to stir casting process. It was observed that the dislocation density, which results from the thermal mismatch between the reinforcement, matrix, and the porosity of composites, has a great influence on the damping capacity of hybrid composites.

Sahoo et al. studied the tribological studies performed in recent one and a half decades on different aluminium matrix composites for their suitability and potentiality for tribological applications [6]. Uvaraja et al. using Taguchi Technique reinforced with mixtures of silicon carbide $(\mathrm{SiC})$ and boron carbide $\left(\mathrm{B}_{4} \mathrm{C}\right)$ particles, known as hybrid composites have fabricated by stir casting technique (liquid metallurgy route), and optimized at different parameters like sliding speed, applied load, sliding time, and percentage of reinforcement by Taguchi method [7]. Shivaraja et al. evaluated the impact strength of Al 356 alloy matrix hybrid composites reinforced with Zirconium Silicate and Silicon Carbide particles has been successfully synthesized by the stir casting method. The results from the study reveal that there is considerable increase in the fracture toughness in the presence of both silicon carbide and zirconium silicate reinforcement in the matrix alloy. The matrix alloy with $2 \% \mathrm{SiC}$ and $6 \% \mathrm{ZrSiO}$ reinforcement has shown high toughness for fracture [8]. Alaneme et al. carried out an investigation on the Fabrication characteristics and mechanical behaviour of rice husk ash-Alumina reinforced Al-Mg-Si alloy matrix hybrid composites. They found that specific strength, percent elongation and fracture toughness of the $2 \mathrm{wt} \%$ RHA containing hybrid composite was higher than that of the single $\mathrm{Al}_{2} \mathrm{O}_{3}$ reinforced and other hybrid composite compositions worked on [9].

With this background, in the present work an attempt has been made to fabricate aluminium alloy and RHA hybrid metal matrix composites by stir casting process. Also, examine the mechanical characterization to investigate whether it could be used in the door-window frame, roof components like beam or column, automobiles, and other construction purposes with economic feasibility.

\section{MATERIALS PREPARATION AND FABRICATION PROCEDURE}

Aluminium alloy $A 356$ was used to make the hybrid composites with $2 \%, 4 \%$, and $6 \%$ rice husk ash, respectively. Stir sand mold casting process was applied to fabricate the specimen. Figure 1 shows the geometry of specimens to analyse the mechanical properties of fabricated hybrid composites. Wooden pattern was used during the casting process. The length, width, and thickness of the specimen are $250 \mathrm{~mm}, 60 \mathrm{~mm}$, and $3 \mathrm{~mm}$, respectively. The chemical compositions, and mechanical properties of $A 356$ material shown in Table 1, and 2, respectively.

Table 1: Chemical compositions of Aluminium alloy, A356

\begin{tabular}{lllllllll}
\hline $\mathrm{Al}$ & $\mathrm{Si}$ & $\mathrm{Fe}$ & $\mathrm{Mn}$ & $\mathrm{Mg}$ & $\mathrm{Zn}$ & $\mathrm{Ti}$ & $\mathrm{Cu}$ & Others \\
\hline $91.2-93.1$ & $6.5-7.5$ & 0.13 & 0.05 & $30-0.45$ & 0.50 & 0.20 & 0.10 & 0.20 \\
\hline
\end{tabular}

Table 2: Mechanical properties of Aluminium alloy, A356

\begin{tabular}{ccc}
\hline $\begin{array}{c}\text { Ultimate Stress } \\
\sigma_{\mathrm{t}}(\mathrm{MPa})\end{array}$ & $\begin{array}{c}\text { Compressive Strength } \\
\sigma_{\mathrm{c}}(\mathrm{MPa})\end{array}$ & $\begin{array}{c}\text { Elongation } \\
\varphi(\%)\end{array}$ \\
\hline 234 & 195 & 2 \\
\hline
\end{tabular}




\subsection{Pattern Preparation}

As the main implementation would be in the window, doorframe, and roof components as a beam or column, the pattern has made like window frame components. Window frame which is fixed with the wall contain three parts: (i) top part, (ii) side part, and (iii) bottom part. Hence, for a rectangular shape frame, two side parts are same. Therefore, three patterns are enough for the experiment. All the patterns are $250 \mathrm{~mm}$ in length, $60 \mathrm{~mm}$ in width, and $3 \mathrm{~mm}$ in thickness. Figure 2(a), (b), and (c) show isometric view of top, side, and bottom part, of a window frame, respectively.

\subsection{Physical Treatment of Rice Husk}

In the present study, rice husk procured from local sources was collected, and has thoroughly washed with water to remove the dust and dried. In order to sustain for further operations, the rice husk is usually dries at room temperature. After the physical treatment, no chemical properties changed normally [10]. Dust, dirt, and other unnecessary substances removed from it for further actions. This treatment was done due to avoid the unwanted foreign piratical in rice husk. Figure 3 shows the rice husk before and after the physical treatment.

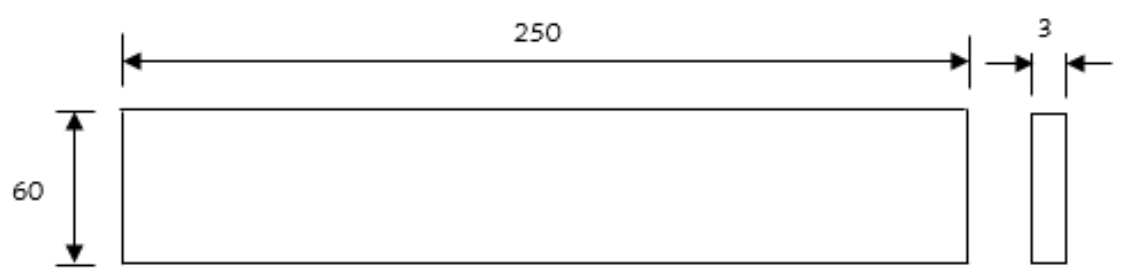

(a)

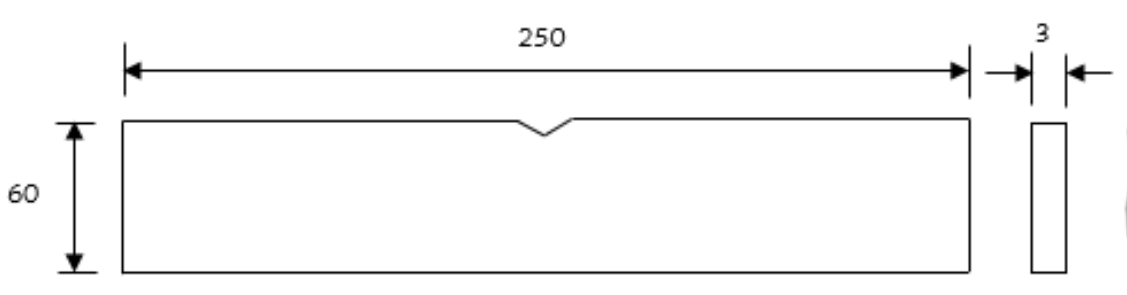

(b)

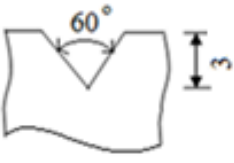

(c)

Figure 1: Geometry and dimensions (in millimetre) of the specimens of fabricated hybrid composites (a) For tensile, compressive, and hardness test, (b) notched specimen for impact test and (c) geometry of $v$-notch.

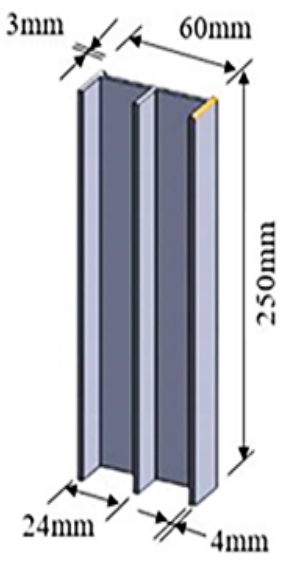

(a)

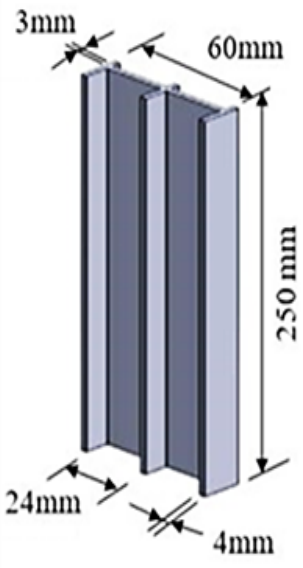

(b)

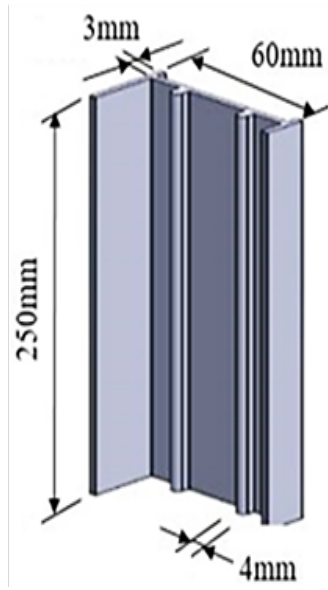

(c)

Figure 2: Window frame fabrication by stir casting process of hybrid composites (a) top part, (b) side part and (c) bottom part. 


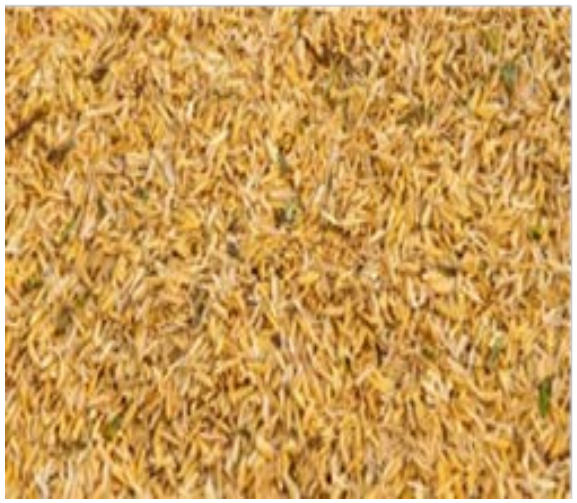

(a)

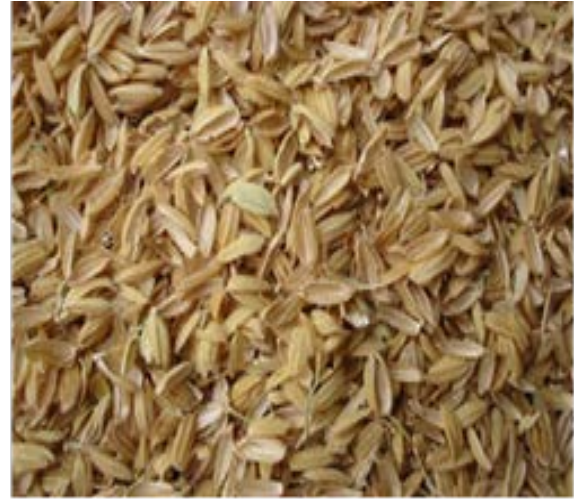

(b)

Figure 3: Rice husk (a) before physical treatment and (b) after physical treatment.

\subsection{Heat Treatment Process of Rice Husk Ash}

After the physical treatment of dry rice husk, it was taken to graphite crucible. By the proper arrangement of furnace and graphite crucible, dried rice husk was then heated up to $150^{\circ} \mathrm{C}$ for one hour. This operation helps to remove the moisture and organic matter. During this operation, the colour of the husk changed from yellowish to black because of charring of organic matter. After that the ash again heated up to $500^{\circ} \mathrm{C}$ to $650^{\circ} \mathrm{C}$ for 6 hours, to remove the carbonaceous material [11]. In this operation, the rice husk completely burns. For obtaining desired properties, the ash is further heated in the electric furnace at $700^{\circ} \mathrm{C}$ for 12 hours. Here, the rice husk ash was used as a filler material. After finalizing this operation and after cooling the ash's colour is completely changed from black to grey or slightly greyish white. The burning process of rice husk is shown in the Figure 4.

After the heat treatment the white rice husk ash $(R H A)$ has observed. For the sake of having proper composite material only the white rice husk ash $(R H A)$ had collected from the mixed specimen by separating the black part and other associated particles. Figure 5 shows the flowchart of rice husk ash preparation.

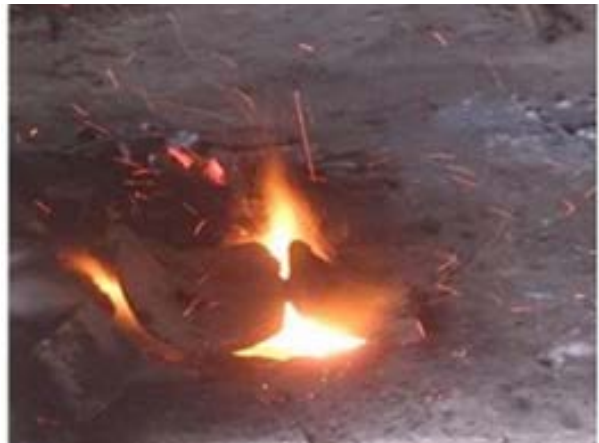

(a)

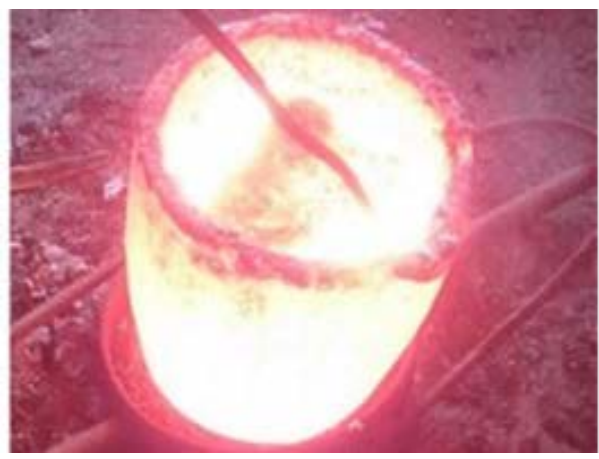

(c)

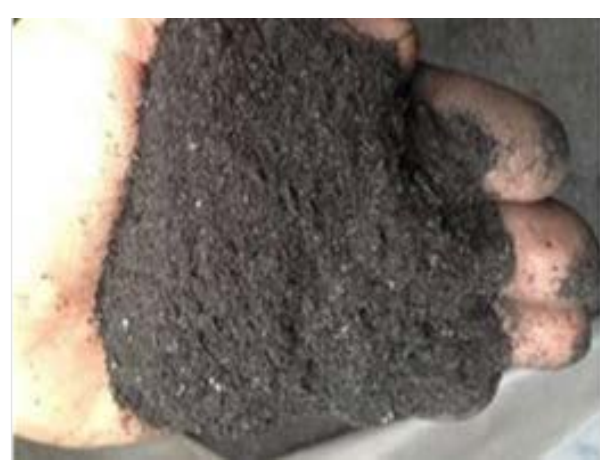

(b)

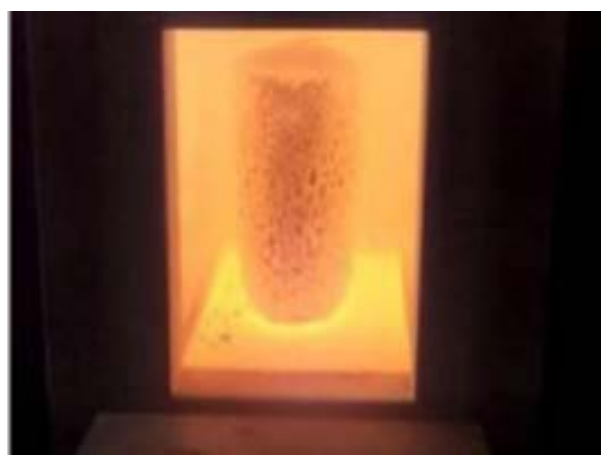

(d)

Figure 4: Preparation of rice husk ash (a) rice husk burning in furnace, (b) rice husk ash, (c) rice husk is being moved to electric furnace and (d) heated in electric furnace. 


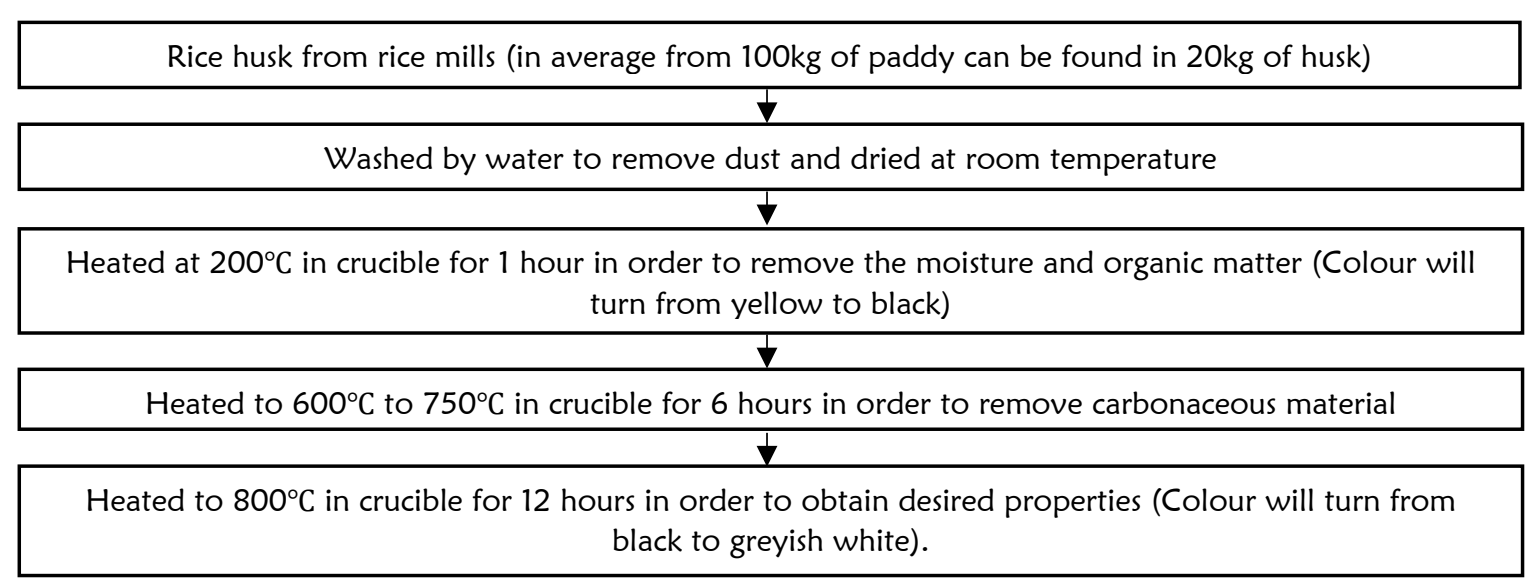

Figure 5: Flow chart representing the process of making rice husk ash sequentially.

\subsection{Preparation of Aluminium Alloy}

Initially, A356 Aluminium-alloy has charged into the graphite crucible. At first the aluminium alloy heated at about $750^{\circ} \mathrm{C}$ till the entire alloy in the crucible melted. Once the molten metal has fully melted, it has stirred manually by the stirrer made up of stainless steel to remove porosity, bubbles inside the melted aluminium alloy [12].

\subsection{Mixing of Rice Husk Ash with Aluminium Alloy (A356)}

In another crucible the rice husk ash (RHA) were preheated to $800^{\circ} \mathrm{C}$ for 1 hour before incorporation into the melt. The molten metal was added into the preheated rice husk ash (RHA) particles at a constant rate during the stirring time. Constant stir has arranged to get a uniform mixture. In this case, manual stir casting done where a leader was used to mix the aluminium with rice husk ash (RHA). Continuous rotation of the leader maintained to mix the aluminium with rice husk ash $(R H A)[12]$.

\subsection{Preparation of Stir Casting}

The sand mold is mainly prepared by green sand which is also known as molding sand. The mold mainly prepared with the help of drag and cope. In order to get uniform solidification, the mold was preheated at $500^{\circ} \mathrm{C}$ in furnace for about 30 minutes. The mixture poured slowly into the mold. Using this process $2 \%, 4 \%$, and $6 \%$ by weight rice husk ash (RHA) particle reinforced composites fabricated. The casted metal matrix composite (MMC) samples examined by different types of destructive and nondestructive testing procedure for further actions.

Type 1: Aluminium alloy $A 356$ with $2 \%$ rice husk ash, $R H A$

Type 2: Aluminium alloy $A 356$ with $4 \%$ rice husk ash, $R H A$

Type 3: Aluminium alloy $A 356$ with $6 \%$ rice husk ash, $R H A$

The arrangements of drag part, cope part, and two parts was attached for pouring. The state of mold after pouring shown in Figure 6(a). After the molten metal was poured, the mold was kept at room temperature to solidify. Then the metal which had poured through the runner, and riser removed by cutting operation. Some grinding operation applied for proper finishing. Figure 6(b) shows the casted window frame. In similar way, specimens for the testing of mechanical properties was also casted. Figure 1 shows the geometry of specimens of hybrid composites to analyse the mechanical properties. $V$-notch cut in some cases to get the impact strength.

\subsection{Experimental Procedure}

The tensile and compressive test was performed by using an electro-mechanical universal testing machine (UTM) equipped with the maximum capacity of the load cell at $3 \mathrm{kN}$. The specimens were placed in the grip of the universal testing machine (UTM) machine, and the test was performed by applying tensile load during tensile test, and compressive load during compressive stress test, respectively until failure at room temperature. The corresponding load, strain was plotted. Then tensile stress, compressive stress, and reduction of area were calculated from the experimental data. Impact testing was carried out on Tinius Olse machine as per procedure mentioned in ASTM D256. Fabricated hybrid composites specimens were placed in vertical position (Izod Test), and hammer was released to make impact on specimen, and $C R T$ reader gives the reading of impact strength. The hardness of the hybrid composites was measured using a Brinell hardness tester machine. 


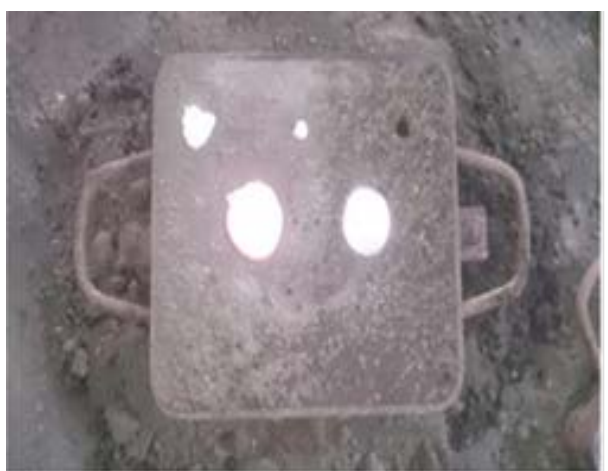

(a)

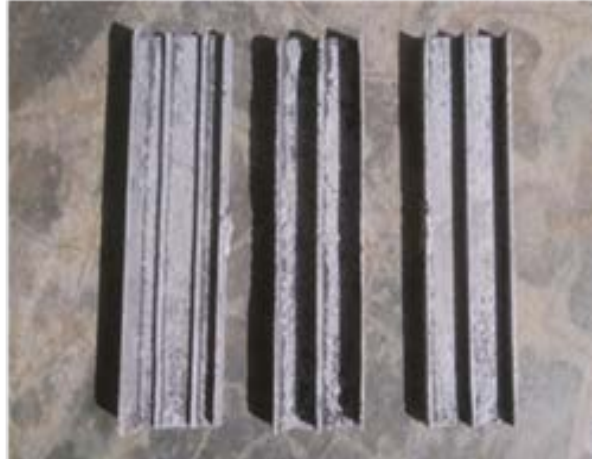

(b)

Figure 6: Fabrication of hybrid composites (a) stir sand mold casting process and (b) window frame after casting.

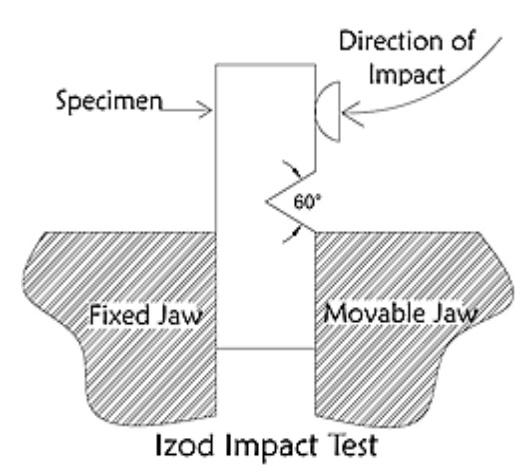

(a)

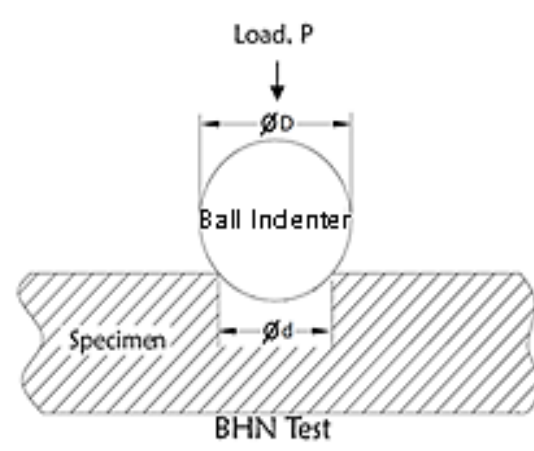

(b)

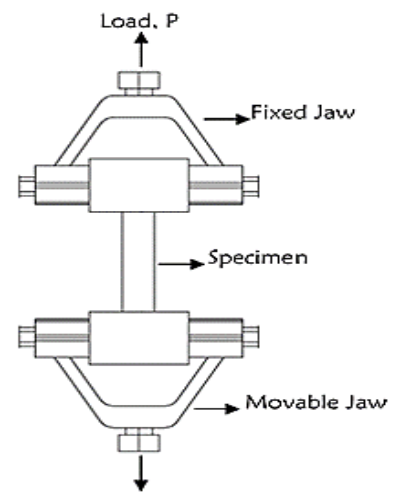

(c)

Figure 7: Evaluation process of (a) Izod impact, (b) BHN and (c) Tensile stress.

\section{EXPERIMENTAL RESULTS AND DISCUSSION}

\subsection{Tensile test}

Every composites and alloys have a great impact on its mechanical properties. Even the effect of their loading imposes great influence on their mechanical properties. A series of investigation were carried out to evaluate the mechanical properties of fabricated hybrid composites. The results of the mechanical properties are shown in Figure 8 . In this study, it has been found that the tensile stress is increased due to the increased percentage of rice husk ash (RHA) in aluminium alloy as shown in Figure 8(a). In the experimental work piece, it has been found that during tensile operation the elongation of different composites increased due to the increased percentage of rice husk ash (RHA) in aluminium alloy.

\subsection{Compressive Test}

The variations of compressive strength with the addition of rice husk was shown in Figure 8(a). From the experimental results, it was observed that the compressive strength was also increased with an increase in the weight percentage of rice husk particles. Due to the hardening of the base alloy by rice husk particles, the compressive strength increased, and the maximum compressive strength was found when $6 \%$ rice husk ash was used in the hybrid composites.

\subsection{Impact Test}

An impact tester can observe the toughness of a material. Generally, notch type specimens are used for impact tests. The purpose of the notch is to serve as a stress concentrator. Izod impact testing machine and one-sided $v$-notched specimens were used to evaluate the impact energy of this hybrid composite. The specimen's length was $120 \mathrm{~mm}$, notch depth was $3 \mathrm{~mm}$, and the angle was $60^{\circ}$. Impact test identifies how much energy a material can absorb. The testing specimens are mainly made of aluminium alloy, which has low hardness and high ductility properties. Therefore, to evaluate the absorbed energy, pendulum was set at the lowest position to get accurate values. Corresponding impact stress is shown in Figure 8(b). 


\subsection{Hardness Test}

The variation of hardness of different combinations of aluminium and rice husk ash reinforcements in the fabricated metal matrix composites (MMCS) was evaluated. Specimens were placed at universal hardness testing machine (UHTM) for testing hardness which was usually consists of a hydraulic system diamond ball indenter. The Brinell hardness number, (BHN) is the ratio of load in kilograms to the impressed area in square millimetres, and is calculated by the following Equation (1), where, $L=$ applied load, $D=$ diameter of load in $\mathrm{mm}, d=$ diameter of impression:

$$
\mathrm{BHN}=\frac{L}{\frac{\pi D}{2}\left(D-\sqrt{\left.\left(D^{2}-d^{2}\right)\right)}\right.}
$$

It is observed that the optimum hardness is achieved for aluminium, and $6 \%$ rice husk ash combination. This occurs due to increases in surface area of the matrix, and the reduced grain sizes. The presence of such hard surface area offers more resistance to plastic deformation, which leads to increase in hardness. In our experimental work piece, it has been found that the hardness is increased when the percentage of rice husk ash (RHA) in fabricated hybrid composites was increased. Figure $8(\mathrm{c})$ shows the hardness number of $2 \%, 4 \%$, and $6 \%$ rice husk ash (RHA) mixed aluminium metal matrix hybrid composites.

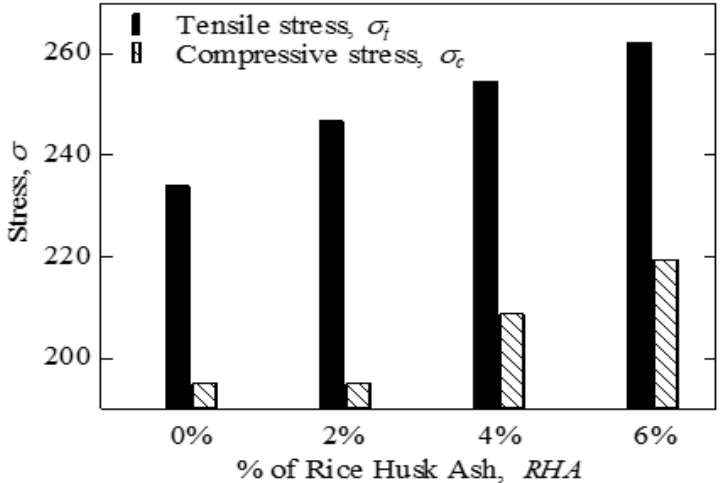

(a)

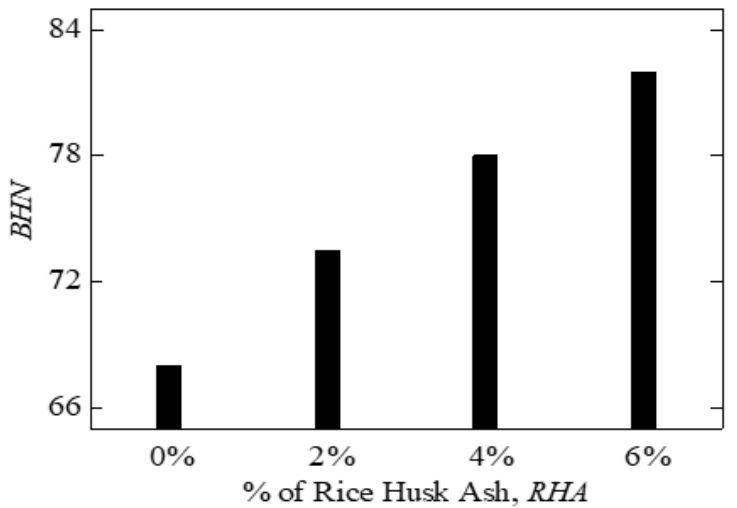

(c)

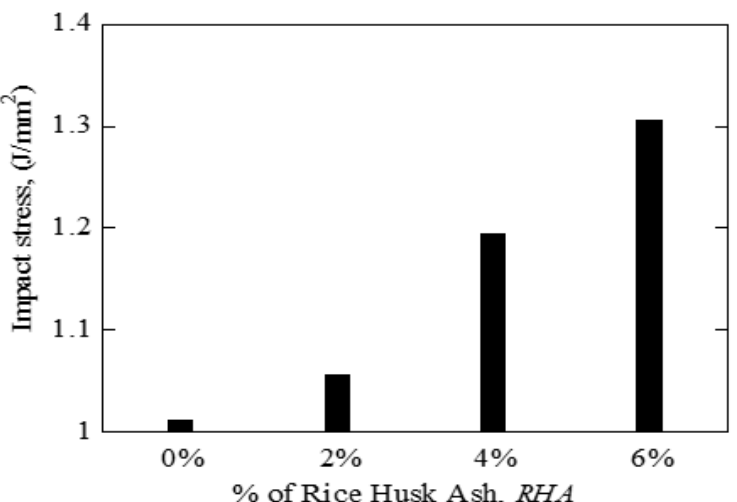

(b)

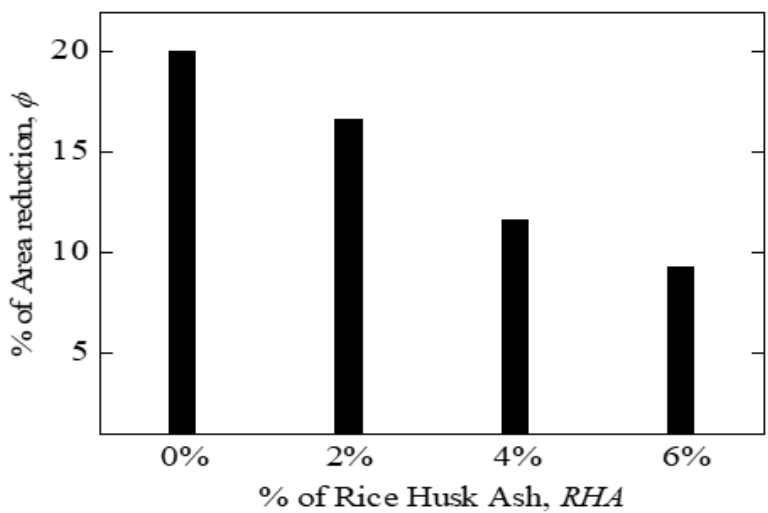

(d)

Figure 8: Mechanical properties of hybrid composites (a) tensile and compressive test, (b) impact test, (c) hardness test and (d) area reduction test.

\subsection{Area Reduction Test}

Figure $8(\mathrm{~d})$ shows the effect of percentage reinforcement of rice husk ash (RHA) on percentage elongation of composites. It was observed that percentage of the area of the composites decreases with the increase of rice husk ash particles. This is due to the increase in hardness of the rice husk ash particles or clustering of the particles. In the experimental work piece, it has been found that during tension operation the cross-sectional area of fabricated hybrid composites increased due to the increasing percentage of rice husk ash $(R H A)$ in aluminium alloy. The reduction in area was determined by using following Equation (2), where, $A_{\circ}=$ original cross section area, $A_{\mathrm{f}}=$ final cross section area:

$$
\text { Reduction in area }(\%)=\frac{A_{0}-A_{f}}{A_{0}} \times 100
$$




\subsection{Microscopic Analysis}

The microstructure of hybrid composites with rice husk ash was examined by using optical microscope and shown in Figure 9. From the microstructure analysis, it is clearly reveals minimal micro porosities in the casting, and the rice husk ash particles are clearly visible. Also, there is a good bonding between metal matrix and rice husk ash $(R H A)$ reinforcements which indicates good bonding strength. Due to these reasons, the mechanical properties such as tensile-compressive stress, impact stress, hardness are increased, and the area reduction rate decreased.

\section{ECONOMIC FEASIBILITY}

It was found that after mixing rice husk ash (RHA), the weight of the hybrid composites was reduced significantly. Aluminium is being highly used where light weight is very important. As the strength, and weight was improved in this experimental study, the aptness of the final composite for other applications will be widespread. The main implementation of the experimented hybrid composites is in window frame, doorframe and roof components as a beam or column, and from the result it was found that A356/RHA is comparatively better than mere A356. According to the cost calculation comparison between raw aluminium, and rice husk ash (RHA) with metal matrix composite $(M M C)$, it was found that total cost was reduced $13 \%$ when $6 \%$ rice husk ash $(R H A)$ was used to fabricate the aluminium-rice husk ash hybrid composites. This calculation was done for $1000 \mathrm{~kg}$ of hybrid composites production.

\section{SWOT ANALYSIS}

SWOT analysis usually performed for evaluating strength, weakness, opportunities, threats and is a structured planning method that evaluates those four elements of any projects or research. For our fabricated aluminium alloy and rice husk ash hybrid composites the SWOT analysis has been done. Figure 10 shows the result of our SWOT analysis. It could be a great opportunity in the light industrial sectors and construction area to use aluminium alloy and rice husk ash hybrid composites with some improved mechanical properties comparing with the pure aluminium alloy. But the drawback is with the increase in tensile strength and hardness the area reduction rate decreases.

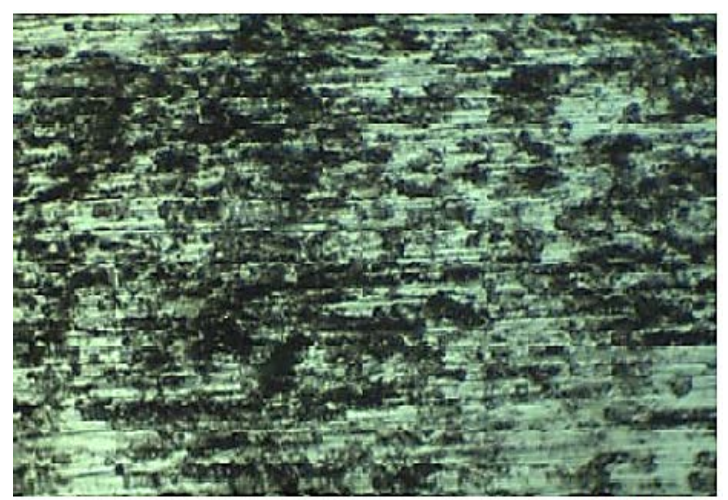

$0.25 \mathrm{~mm}$

(a)

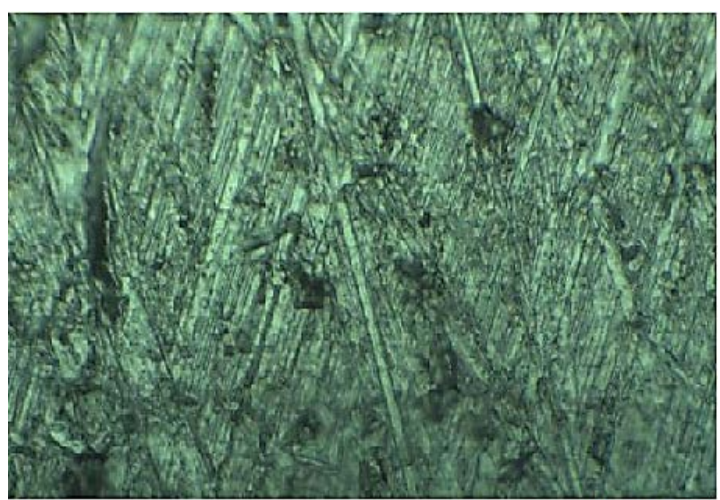

$0.25 \mathrm{~mm}$

Figure 9: Microstructure of aluminium alloy- various percentages of rice husk ash (RHA) hybrid composites (a) $6 \%$ and (b) $2 \%$.

\section{Strength \\ - Improved mechanical properties \\ - Environment friendly \\ - Cost effective \\ - Recyclability}

\section{Opportunity \\ - Could be used in Automobiles construction, and other industries}
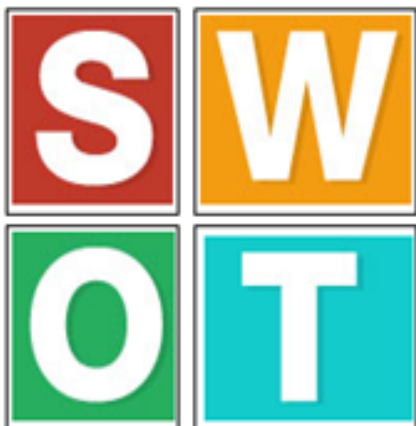

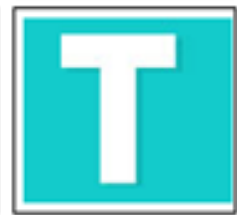

Weakness

- Area reduction rate decreases

\section{Threats}

- The mechanical properties can be changed for the improper mixing of RHA and Aluminium alloy

Figure 10: SWOT analysis of aluminium alloy-rice husk ash hybrid composites. 


\section{CONCLUSIONS}

In this study, rice husk ash particles were successfully incorporated in A356 alloy by using stir casting techniques. The use of rice husk ash $(R H A)$ for the fabrication of hybrid composites can turn agricultural waste into industrial assets. A series of tests were conducted to investigate the mechanical properties of fabricated aluminium alloy-rice husk ash metal matrix hybrid composites. Also, fabricated window frame using this hybrid composites shows the application feasibility, and improve mechanical properties. Therefore, it could be used in the door-window frame, roof components like beam or column, automobiles, and other construction purposes. Experimental results showed that the mechanical properties of aluminium metal matrix hybrid composites have increased with the increasing percentages of rice husk ash $(R H A)$ in the hybrid metal matrix composites except the area reduction property due to the elongation decreases with the increase in rice husk ash content. Production of cost effective aluminium composites could have incorporated by using rice husk ash to get improved hardness, and strength.

\section{ACKNOWLEDCEMENT}

The authors are grateful to Professor Tarapada Bhowmick for his valuable suggestions in this study.

\section{REFERENCES}

1. Itskos, G., Rohatgi, P. K., Moutsatsou, A., Defouw, J. D., Koukouzas, N., Vasilators, C. \& Schultz, B. F. (2012). Synthesis of $A 356 \mathrm{Al}-\mathrm{High}-\mathrm{Ca}$ fly ash composites by pressure infiltration technique and their characterization. Journal of Materials Science, 47(9), 4042-4052.

2. Rohatgi, P. K. (1993). Metal matrix composites. Defence Science Journal, 43(4), 323-349.

3. Zahi, S. \& Daud, A. R. (2011). Fly ash characterization and application in Al-based Mg alloys. Materials and Design, $32(3), 1337-1346$.

4. Mišković, Z., Bobić, I., Tripković, S., Rac, A. \& Vencl, A. (2006). The Structure and Mechanical Properties of an Aluminium A356 Alloy Base Composite with $\mathrm{Al}_{2} \mathrm{O}_{3}$ Particle Additions. Tribology in Industry, 28(3-4), 23-27.

5. Prasad, D. S. \& Shoba, C. (2016). Experimental evaluation onto the damping behavior of $\mathrm{Al} / \mathrm{SiC} / \mathrm{RHA}$ hybrid composites. Journal of Materials Research and Technology, 5(2), 123-130.

6. Sahoo, P. \& Ghosh, S. (2011). Tribological behavior of aluminium metal matrix composites-A review. Journal of Tribology Research, 2(1), 1-14.

7. Uvaraja, V. C. \& Natarajan, N. (2012). Optimization of Friction and Wear Behavior in Hybrid Metal Matrix Composites Using Taguchi Technique. Journal of Minerals and Materials Characterization and Engineering, 11(8), 757-768.

8. Shivaraja, H. B. \& Parveen, K. B. S. (2017). Experimental Determination and Analysis of Fracture Toughness of MMC. International Journal of Science and Research, 2319-7064.

9. Alaneme, K. K., Akintunde, I. B. \& Olubambi, P. A. (2013). Fabrication characteristics and mechanical behaviour of rice husk ash - Alumina reinforced Al-Mg-Si alloy matrix hybrid composites. Journals of Materials Research and Technology, 2, 60-67.

10. Prasad, D. S. \& Krishna, A. R. (2011). Production and Mechanical Properties of A356.2/RHA Composites. International Journal of Advanced Science and Technology, 33, 51-58.

11. Das, S., Dan, T. K., Prasad, S. V. \& Rohatgi P. K. (1986). Aluminium alloy-rice husk ash particle composites. Journal of Materials Science Letters, 5(5), 562-564.

12. Peter A. O. \& Kenneth K. A. (2013). Corrosion and wear behaviour of rice husk ash - Alumina reinforced Al-MgSi alloy matrix hybrid composites. Journal of Materials Research and Technology, 2(2), 188-194. 